\title{
Restoration of the integrity of rat caeco-colonic mucosa by resistant starch, but not by fructo-oligosaccharides, in dextran sulfate sodium-induced experimental colitis
}

\author{
Noëlle M. Moreau ${ }^{1,3}$, Lucile J. Martin ${ }^{1,3 *}$, Claire S. Toquet ${ }^{3,4,5}$, Christian L. Laboisse ${ }^{3,4,5}$, \\ Patrick G. Nguyen ${ }^{1,3}$, Brigitte S. Siliart ${ }^{1,3}$, Henri J. Dumon ${ }^{1,3}$ and Martine M. J. Champ ${ }^{2,3}$ \\ ${ }^{1}$ Unité de Nutrition et d'Endocrinologie, Ecole Nationale Vétérinaire, Nantes, France \\ ${ }^{2}$ Unité des Fonctions Digestives et Nutrition Humaine, Institut National de la Recherche Agronomique, \\ Nantes, France \\ ${ }^{3}$ Centre de Recherche en Nutrition Humaine, Nantes, France \\ ${ }^{4}$ INSERM U539, Faculté de Médecine, Nantes, France \\ ${ }^{5}$ Service d'Anatomie Pathologique, CHU, Nantes, France
}

(Received 15 April 2002 - Revised 17 February 2003 - Accepted 20 February 2003)

\begin{abstract}
Butyrate is recognised as efficient in healing colonic inflammation, but cannot be used as a long-term treatment. Dietary fibre that produces a high-butyrate level when fermented represents a promising alternative. We hypothesised that different types of dietary fibre do not have the same efficiency of healing and that this could be correlated to their fermentation characteristics. We compared short-chain fructo-oligosaccharides (FOS) and type 3 resistant starch (RS) in a previously described dextran sulfate sodium (DSS)-induced colitis model. Seventytwo Sprague-Dawley rats received water (control rats) or DSS (50 g DSS/l for $7 \mathrm{~d}$ then $30 \mathrm{~g} \mathrm{DSS} / 1$ for 7 (day 7) or 14 (day 14) d). The rats were fed a basal diet (BD), or a FOS or RS diet creating six groups: BD-control, BD-DSS, FOS-control, FOS-DSS, RS-control and RS-DSS. Caeco-colonic inflammatory injuries were assessed macroscopically and histologically. Short-chain fatty acids (SCFA) were quantified in caeco-colon, portal vein and abdominal aorta. At days 7 and 14, caecal and distal macroscopic and histological observations were improved in RS-DSS compared with BD-DSS and also with FOS-DSS rats. Caeco-colonic SCFA were reduced in FOS-DSS and RS-DSS groups compared with healthy controls. The amount of butyrate was higher in the caecum of the RS-DSS rats than in the BD-DSS and FOS-DSS rats, whereas distal butyrate was higher in FOS-DSS rats. Partially explained by higher luminal levels of SCFA, especially butyrate, the healing effect of RS confirms the involvement of some types of dietary fibre in inflammatory bowel disease. Moreover, the ineffectiveness of FOS underlines the importance of the type of dietary substrate.
\end{abstract}

Fructo-oligosaccharide: Resistant starch: Dextran sulfate sodium: Short-chain fatty acids: Butyrate

Acetate, propionate and butyrate, the three major short-chain fatty acids (SCFA) are the endproducts of the colonic anaerobic fermentation of dietary fibre. Luminal SCFA are oxidation substrates for the colonocyte (Clausen \& Mortensen, 1994) and have trophic effect on healthy gut epithelial cells (Sakata, 1987). Systemic SCFA also influence the intestinal structure (Tappenden \& McBurney, 1998). Among SCFA, butyrate is known to represent the major fuel source for the colonocyte (Roediger, 1980a, 1982; Fleming et al. 1991) and to be essential for mucosa health (Basson \& Sgambati, 1998). Indeed, it was shown that a lack of butyrate has deleterious effects on the colonic mucosa (Firmansyah et al. 1989; Roediger, 1993).

Previous studies have demonstrated that SCFA, especially butyrate, have a beneficial trophic effect on inflamed caeco-colonic mucosa of human subjects
(Scheppach et al. 1992, 1997; Frankel et al. 1994) or experimental animal colitis (Butzner et al. 1996). Many studies have shown that inflamed rat (Ahmad et al. 2000) or human (Roediger, 1980b; Chapman et al. 1994; Den Hond et al. 1998) colonocytes showed impairment of butyrate oxidation.

Butyrate enemas have shown their benefit for mucosal health (Breuer et al. 1991; Steinhart et al. 1994) in patients suffering from Crohn's disease or ulcerative colitis, which encompass the two major forms of inflammatory bowel disease. However, this positive effect disappears when administered per os (Kanauchi et al. 1999). Hence, among therapeutic alternatives, dietary fibre that produces a high butyrate proportion when fermented in the large intestine, and which could be ingested as a functional food, seems a promising and a more realistic treatment 
for patients. However, no results are available on what the characteristics of the best dietary substrates to heal inflammatory bowel disease are. In the present paper, in order to assess their healing efficiency, two substrates, well known to yield a large amount of butyrate after fermentation, were tested on a previously described model of colitis based on a dextran sulfate sodium (DSS) administration. In a few days, this continuous DSS treatment was able to induce stable chronic inflammation, predominantly with caecal and distal injuries (Moreau et al. 2002). The two fibres were selected according to their fermentation kinetics. When considering the caeco-colon, fructo-oligosaccharides (FOS) are known to be rapidly fermented, whereas resistant starch (RS) is more slowly degraded and can reach the distal part of the colon (Le Blay et al. 1999a,b).

The objective of the present study was to examine which substrate induced the best recovery of mucosa by looking at morphological macroscopic and histological criteria. Indeed, we made the hypothesis that these fibres, which have different fermentation patterns, would not have the same capacity to restore the inflamed colonic mucosa and that this effect could be partly caused by their ability to be fermented to produce SCFA, especially butyrate.

\section{Methods}

\section{Animals and housing}

Seventy-two male Sprague-Dawley rats (Harlan, Gannat, France), weighing 310 (SEM 10) g at arrival, were used for the present experiment. They were housed individually in cages designed to avoid coprophagy, and a light-dark cycle (light on 08.00-20.00 hours) was used. The animals were allowed free access to diet and water until killing. The experiment was carried out according to the French animal welfare rules (Decree no. 2002/464, 29 May 2001) and approved by the Nantes Ethics Committee for Laboratory Animals.

\section{Diets}

Three experimental diets with different fibre contents (Table 1) were specifically formulated for the experiment (INRA, Jouy-en-Josas, France). The basal diet (BD) was a low-fibre diet containing $20 \mathrm{~g}$ cellulose $/ \mathrm{kg}$. The FOS diet was enriched with short-chain FOS (Actilight P; Beghin-Meiji Industries, Paris, France) and the RS diet with RS type 3 (retrograded Hylon 7, high amylomaize starch, Novelose 330; National Starch and Chemical Ltd, Manchester, UK). They were formulated to provide $60 \mathrm{~g}$ indigestible carbohydrate + cellulose $/ \mathrm{kg}$ DM . The metabolisable energy contents $(\mathrm{kJ} / \mathrm{g}$ DM) were $17.30,16.76$ and 16.34 for the BD and FOS and RS diets respectively. Water, food intake and body weight were recorded daily.

\section{Colitis induction}

At the beginning of the experiment, after a $7 \mathrm{~d}$ adaptation to the diet and housing conditions, the animals were randomly divided into two groups. The first group received
Table 1. Composition of the three experimental diets $(\mathrm{g} / \mathrm{kg})$

\begin{tabular}{lrrr}
\hline Diet... & Basal & FOS & RS \\
\hline Short-chain FOS* & 0 & 63 & 0 \\
RS (type 3) $†$ & 0 & 0 & 115 \\
Pregelatinised maize starch $\ddagger$ & 650 & 587 & 535 \\
Casein & 204 & 204 & 204 \\
DL-Methionine & 4 & 4 & 4 \\
Refined maize oil & 18 & 18 & 18 \\
Lard & 58 & 58 & 58 \\
Cellulose§ & 20 & 20 & 20 \\
Minerals & 44 & 44 & 44 \\
Vitamins & 2 & 2 & 2 \\
\hline
\end{tabular}

FOS, fructo-oligosaccharide; RS, resistant starch.

${ }^{*}$ Actilight P; Beghin-Meiji Industries, Paris, France.

† Novelose 330; National Starch and Chemical Ltd, Manchester, UK.

$\ddagger$ Cerestar SF 12018; Cerestar, Vilvoorde, Belgium.

$\S$ Arbocel BOO; Arbocel, Marne-la-Vallée, France.

$50 \mathrm{~g} \mathrm{DSS} / 1$ in water (DSS group) (DSS molecular mass 36-44 kDa; ICN Pharmaceuticals, Orsay, France) for $7 \mathrm{~d}$ (day 0 ). Then, the concentration of the DSS solution was reduced to $30 \mathrm{~g} / \mathrm{l}$ for $7 \mathrm{~d}$ (day 7 ) or $14 \mathrm{~d}$ (day 14) in order to induce a stable chronic active colitis as previously described (Moreau et al. 2002). The second group was free from DSS throughout the experiment and received drinking water (control group). As shown in Fig. 1, during the adaptation period and the $50 \mathrm{~g}$ DSS/ 1 period, all the animals (control and DSS groups) received the BD. The rats were then randomly assigned to one of the three experimental diets (BD, FOS and RS diets). The six groups were identified as: BD-control and BD-DSS, FOS-control and FOS-DSS, RS-control and RS-DSS.

Six rats from each of the six groups were killed at day 7 (water or $50 \mathrm{~g} \mathrm{DSS} / 1$ for $7 \mathrm{~d}$ then $30 \mathrm{~g} \mathrm{DSS} / 1$ for $7 \mathrm{~d}$ ), and six rats at day 14 (water or $50 \mathrm{~g}$ DSS/l for $7 \mathrm{~d}$ then $30 \mathrm{~g} \mathrm{DSS} / 1$ for $14 \mathrm{~d}$ ).

\section{Collection of digestive tissues and contents}

After being anaesthetised by intraperitoneal injection of $15 \mathrm{mg}$ xylazine $/ \mathrm{kg}$ (Bayer Pharma, Puteaux, France) and intramuscular injection of $55 \mathrm{mg}$ ketamine $/ \mathrm{kg}$ (Mérial, Lyon, France), the rats were laparotomised and blood samples were collected from the portal vein and abdominal aorta with an infusion set. The animals were then killed by an intra-cardiac injection of sodium pentobarbital (Vétoquinol, Lure, France). The caecum and the colon were resected after ligature of the ileo-caecal junction up to the rectal ampoule. The entire colon length was measured and the three segments (caecum, proximal and distal colon) were then removed and weighed to assess inflammation. Afterwards, each was cut longitudinally and tissues and digestive contents were recovered. The whole procedure occurred between 09.30 and 10.30 hours for all rats.

\section{Macroscopic and histological scores}

Caecum, proximal and distal colon were gently cleaned with isotonic solution $(9 \mathrm{~g} \mathrm{NaCl} / \mathrm{l}$; Aguettant, Lyon, France), and colitis activity was scored by visual 


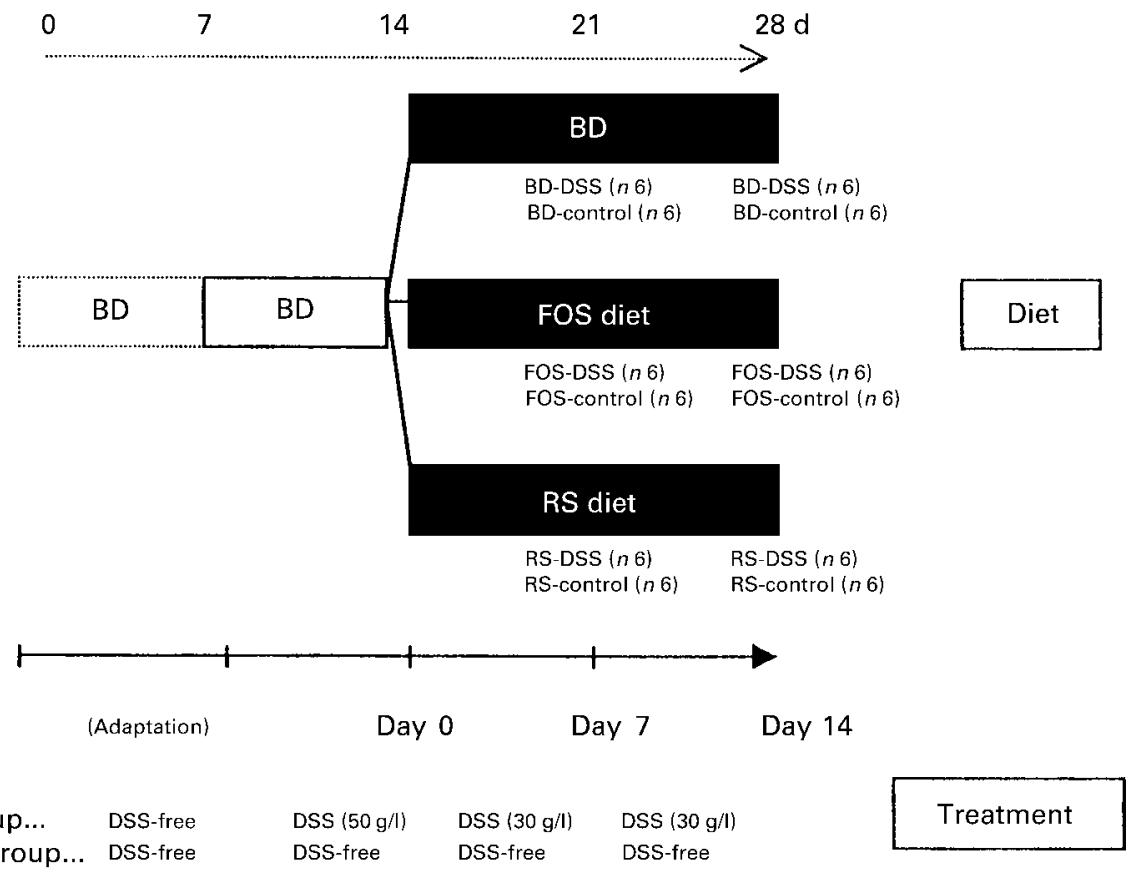

Fig. 1. Experimental protocol. BD, basal diet; FOS, fructo-oligosaccharide; RS, resistant starch; DSS, dextran sulfate sodium. For details of diets, see Table 1.

assessment (assessors were blinded to the treatment group), using a scale described by Appleyard \& Wallace (1995) with slight modifications: tissues adhesions ( 0 , none; 1 , minor; 2 , severe), caecal mucosa ( 0 , normal; 1 , hyperaemia; 2, blood in contents; 3, ulcerations), diarrhoea ( 0 , none; 1, mild; 2, severe), blood in the contents ( 0 , none; 1 , in one-third of the colon; 2 , in two-thirds of the colon; 3 , in the entire colon), colonic mucosa thickening $(0$, normal; 1 , moderate; 2 , severe), colonic ulcerations ( 0 , any site; 1 , focal hyperaemia; 2 , limited ulcerations; 3 , ulcerations extending more than $10 \mathrm{~mm}$ along the length of the colon). The total macroscopic score corresponded to the sum of these partial scores.

Tissue was fixed in neutral buffered formalin $(100 \mathrm{ml} / \mathrm{l})$, dehydrated, and paraffin-embedded. Sections $(5 \mu \mathrm{m})$ were stained with haematoxylin and eosin, and scored by considering the loss of mucosal architecture (scored $0-3)$, cellular infiltration $(0-3)$, muscle thickening $(0-3)$, crypt abcesses $(0-1)$ and goblet cell depletion $(0-1)$ (maximum score 11) (Appleyard \& Wallace, 1995; Moreau et al. 2002).

\section{Short-chain fatty acid quantification in caeco-colonic contents}

A sample of the contents of three gut segments was removed and homogenised in $2 \mathrm{ml}$ mercuric chloride ( $1 \mathrm{~g} / \mathrm{l}$; Merck, Darmstadt, Germany). After centrifugation, the supernatant fraction was frozen immediately at $-80^{\circ} \mathrm{C}$ and stored until later analysis. SCFA concentrations were quantitated by GC (GC-6890; Hewlett Packard, les Ulis, France) using a $1 \mu \mathrm{m}$ FFAP column $(30 \mathrm{~m} \times 0.53 \mathrm{~mm})$ (Hewlett Packard) and flame ionisation detector, using the procedure described by Brighenti (1997), slightly modified, with 2-ethylbutyric acid as internal standard. SCFA were expressed as molar ratios, $\mu$ mol per caeco-colonic compartment ('amount' of SCFA per compartment) and $\mu \mathrm{mol} / \mathrm{g}$ wet digestive contents ('concentrations' of SCFA in each compartment). In order to verify if DSS inhibits the fermentative intensity, SCFA were expressed as $\mu \mathrm{mol} / \mathrm{g}$ food DM intake (mean value of the last $3 \mathrm{~d}$ ) to take into account the possible differences in food intake between DSS and control rats and between the different diets.

\section{Short-chain fatty acid measurements in blood samples}

Total arterial or venous blood was collected in a heparinised tube, centrifuged at $2100 \mathrm{~g}$ for $10 \mathrm{~min}$, and plasma frozen at $-80^{\circ} \mathrm{C}$. Plasma SCFA measurements were performed using isovaleric acid (Sigma-Aldrich, St Quentin-Fallavier, France) as internal standard with the procedure described by Brighenti (1997).

\section{Calculations and statistics}

Levels of SCFA appearing in the portal blood were calculated by arterio-venous difference $(\Delta)$ between concentrations obtained in the portal vein and in the abdominal aorta (Demigné \& Rémésy, 1982). The objective of calculating this difference was to subtract the endogenous part of SCFA (which is not of digestive origin) from the portal concentrations, in order to consider only SCFA that a priori came solely from caeco-colonic fermentation. Portal SCFA were also expressed as molar ratio $\left(\Delta \mathrm{C}_{\mathrm{x}} / \Delta \mathrm{SCFA}\right)$.

Results were expressed as mean values with their standard errors, and $n$ refers to the number of rats in each of the six groups. Macroscopic and histological scores were compared using the non-parametric Kruskal-Wallis test. When a 
significant effect $(P<0.05)$ was observed, diets were compared separately using a Mann-Whitney test. The other variables described in the present paper were analysed by ANOVA with treatment (DSS $v$. control), diet and time (day 7 and day 14) as main factors. When there was no significant interaction effect in the two-way (treatment $X$ diet) or three-way (treatment $\times$ diet $\times$ time of killing) comparisons, we conducted a one-way comparison, whereas two-way or three-way comparisons were maintained when the $P$ value of two-way or three-way interaction effect first was $<0.05$. When the tested effect was significant, the differences between mean values were assessed by contrasts analysis using Super ANOVA V 1.11 (Abacus Concepts Inc., Berkeley, CA, USA). For all calculations, the accepted level of statistical significance was $P<0.05$.

\section{Results}

\section{Daily consumption}

No significant difference either in the DSS consumption (Table 2) or in the water:diet consumption ratio was found among BD, FOS and RS groups. In the control group, daily food and water intake were not affected by the type of diet (BD, FOS or RS diet). Diet and DSS consumption of rats fed BD, FOS and RS between days
0 and 7 and between days 7 and 14 (for rats killed at day 14) (see p. 76 and Fig. 1) are indicated in Table 2. In the DSS rats, no difference in food intake appeared between days 0 and 7. Conversely, the FOS-DSS rats had a lower food intake between days 7 and 14 compared with the BD-DSS rats (NS) and RS-DSS rats $(P=0 \cdot 047)$.

\section{Body-weight gain}

In the control group, body-weight gain was not influenced by the type of diet (results not shown). In the DSS group, the greatest weight loss was observed in the FOS-DSS group (Table 2). Nevertheless, body weight was stable between days 7 and 14 among the groups.

\section{Length and weight of the colon and weight of the caecum}

Macroscopic variables differed significantly according to the treatment DSS $v$. control (length of the colon $P=0.0001$, weight of the caecum $P=0.0002$, weight of the colon $P=0 \cdot 0001)$. Neither the type of diet nor the time of killing (day 7 or 14) had a significant effect. However, at day 14 the colons of RS-DSS rats tended to be longer than FOS-DSS (NS) and BD-DSS rats $(P=0 \cdot 061)$ (Table 3). While the FOS-DSS and BD-DSS rats had significantly heavier caeca and colons than the corresponding

Table 2. Diet intake, dextran sulfate sodium (DSS) intake and body-weight gain of rats fed basal, fructo-oligosaccharide (FOS) or resistant starch (RS) diet for 7 (day 7) or 14 (day 14) d and treated with $50 \mathrm{~g}$ DSS/l (7 d) then $30 \mathrm{~g} \mathrm{DSS/l} \mathrm{for} 7$ (day 7 ) or 14 (day 14) d*

(Mean values with their standard errors for six rats per group)

\begin{tabular}{|c|c|c|c|c|c|c|c|c|c|c|c|c|}
\hline \multirow{3}{*}{$\begin{array}{l}\text { Day... } \\
\text { Diet }\end{array}$} & \multicolumn{4}{|c|}{ Diet intake (g/d) } & \multicolumn{4}{|c|}{ DSS intake (g/d) } & \multicolumn{4}{|c|}{ Body-weight gain $†$} \\
\hline & \multicolumn{2}{|c|}{$0-7$} & \multicolumn{2}{|c|}{$7-14$} & \multicolumn{2}{|c|}{$0-7$} & \multicolumn{2}{|c|}{$7-14$} & \multicolumn{2}{|c|}{$0-7$} & \multicolumn{2}{|c|}{$0-14$} \\
\hline & Mean & SEM & Mean & SEM & Mean & SEM & Mean & SEM & Mean & SEM & Mean & SEM \\
\hline Basal & $12 \cdot 0^{a}$ & $1 \cdot 1$ & $14 \cdot 5^{\mathrm{ab}}$ & 1.0 & $15 \cdot 2^{a}$ & $1 \cdot 0$ & $13 \cdot 9^{a}$ & 0.6 & $-0.03^{a}$ & 0.02 & $0.02^{a}$ & 0.02 \\
\hline FOS & $10 \cdot 3^{a}$ & 0.5 & $12 \cdot 5^{\mathrm{a}}$ & 0.6 & $15 \cdot 7^{a}$ & 0.7 & $15 \cdot 7^{a}$ & $1 \cdot 2$ & $-0.12^{\mathrm{b}}$ & 0.04 & $-0.09^{b}$ & 0.03 \\
\hline RS & $11.9^{a}$ & $1 \cdot 1$ & $14 \cdot 8^{\mathrm{b}}$ & $1 \cdot 0$ & $16 \cdot 5^{a}$ & 0.7 & $15 \cdot 4^{\mathrm{a}}$ & 0.8 & $-0.02^{a b}$ & 0.03 & $-0.01^{a b}$ & 0.05 \\
\hline
\end{tabular}

${ }^{a, b}$ Mean values within a column with unlike superscript letters were significantly different $(P<0.05)$

${ }^{*}$ For details of diets and procedures, see Table 1, Fig. 1 and p. 76.

† Body-weight gain = (weight at day 7 (or 14) - weight at the beginning of the experiment)/weight at the beginning of the experiment.

Table 3. Changes in the length of the colon, the weight of the caecum and the colon of rats fed basal, fructo-oligosaccharide (FOS) or resistant starch (RS) diet for 7 (day 7 ) or 14 (day 14) d and treated with water (control group) or $50 \mathrm{~g}$ dextran sulfate sodium (DSS)/l (7 d) then $30 \mathrm{~g}$ DSS/l for 7 (day 7 ) or 14 (day 14) $d^{*}$

(Mean values with their standard errors for six rats per group)

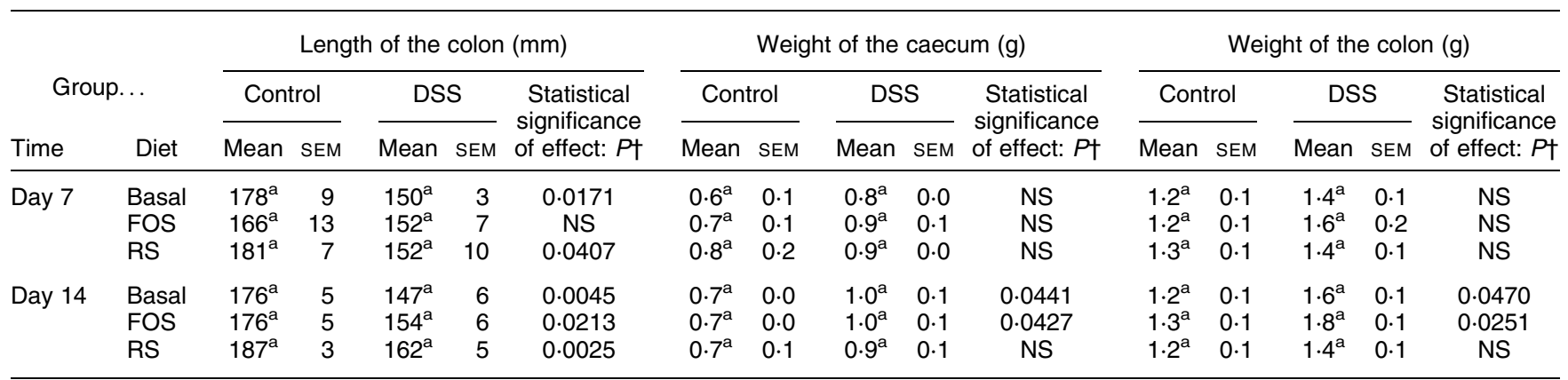

a,b Mean values with unlike superscript letters were significantly different $(P<0.05)$.

${ }^{*}$ For details of diets and procedures, see Table 1, Fig. 1 and p. 76.

tDSS $v$. control. 
control rats, there was no difference between the RS-DSS and RS-control rats. Moreover, FOS-DSS colons were therefore heavier than RS-DSS $(P=0 \cdot 0511)$ (Table 3).

\section{Macroscopic score}

Whatever the time of killing, the control rats' score values were zero. In DSS-treated rats, there was no difference in the score between diets at day 7: 6.6 (SEM 1.1), 7.7 (SEM 1.1) and 6.8 (SEM 1.2) for the BD-, FOS- and RS-DSS groups respectively. However, at day 14 the macroscopic score of the RS-DSS rats (2.7 (SEM 0.6)) was significantly lower than the BD-DSS (6.7 (SEM $0.9), \quad P=0.0082$ ) and FOS-DSS rats (6.1 (SEM 1.5), $P=0.0306$ ). Total score and all the variables included in the macroscopic score at day 14 are detailed in Fig. 2.

\section{Histological assessments}

Histological scores of control groups were zero. At day 7 (Fig. 3(a)) and at day 14 (Fig. 3(b)), histological scores measured in the caecum were significantly $(P<0.05)$ lower in RS-DSS than in BD-DSS rats and in FOS-DSS rats (at day 7). There was no difference between diets in the proximal colon. In the distal colon, the RS diet significantly $(P<0.05)$ decreased the histological score compared with the BD at days 7 and 14 .

The total histological score (caecum+ proximal+distal scores) was significantly lower for RS-DSS than BD-DSS $(P=0.0008$ at day $7, P=0.0124$ at day 14$)$ and than FOS-DSS $(P=0.0195$ at day $7, P=0.0406$ at day 14$)$.

\section{Caeco-colonic fermentations}

Effect of dextran sulfate sodium on the caeco-colonic measurements of short-chain fatty acids ( $\mu \mathrm{mol}$ or $\mu \mathrm{mol} / \mathrm{g}$ wet contents). Whatever the diet, the treatment and the time of killing, the amount of SCFA ( $\mu$ mol) was considerably higher in the caecum than in proximal and distal colon (Table 4). In the caecum, SCFA contents were lower when the rats received the DSS treatment compared with healthy controls. Conversely, proximal and distal amount of SCFA did not vary with DSS (except for RS at day 7).

When results were expressed as concentrations $(\mu \mathrm{mol} / \mathrm{g}$ wet contents), except in the caecum at day 7, digestive SCFA of rats fed BD were not modified by the DSS treatment. Conversely, caeco-colonic SCFA concentrations of rats fed the RS- or FOS-enriched diets were significantly $(P<0.05)$ reduced with DSS compared with healthy controls (Table 4).

Effect of dextran sulfate sodium on the intensity of fermentation ( $\mu \mathrm{mol} / \mathrm{g}$ DM intake). The consequences of a DSS-induced inflammation on the intensity of fermentation (SCFA measurements expressed as $\mu \mathrm{mol} / \mathrm{g} \mathrm{DM}$ intake) differed among diets. DSS treatment did not modify proximal and distal SCFA measurements expressed as $\mu \mathrm{mol} / \mathrm{g}$ DM intake. As previously shown (Moreau et al. 2002), DSS reduced the fermentative abilities of rats fed for $7 \mathrm{~d}$ (day 7) with a low-fibre diet (BD) $(P=0.0249)$, but this inhibition disappeared at day 14. In contrast, when DSS-treated rats were fed the diet supplemented with FOS, caecal fermentation was strongly inhibited at day 7 (8.1 (SEM 1.8) v. 25.0 (SEM 2.5) $\mu \mathrm{mol}$ SCFA/g DM intake for control, $P=0.0004)$ and at day $14(12.9$ (SEM 2.1) v. 30.6 (SEM 4.2) $\mu \mathrm{mol} / \mathrm{g} \mathrm{DM}$ intake for controls, $P=0.0003)$. Conversely, for RS rats, no change appeared at day 7 between control (25.4 (SEM 2.6) $\mu \mathrm{mol} / \mathrm{g}$ DM intake) and DSS groups (18.9 (SEM 3.6) $\mu \mathrm{mol} / \mathrm{g} \mathrm{DM}$ intake). At day 14 , there was a trend of decrease in caecal SCFA by DSS treatment (13.5 (SEM 4.1) v. $22.6($ SEM 2.1) $\mu \mathrm{mol} / \mathrm{g}$ $\mathrm{DM}$ intake for controls, $P=0.0578)$.

Effect of dextran sulfate sodium on short-chain fatty acid molar ratio. Table 4 also summarises the qualitative disturbances of caeco-colonic fermentation induced by DSS administration. For the BD-DSS rats, the caecal butyrate molar ratio was higher at day 7 compared with control groups. With FOS diet, the acetate molar ratio was reduced in DSS groups at day 7 in the caecum and the proximal colon, whereas the propionate molar ratio of DSS rats
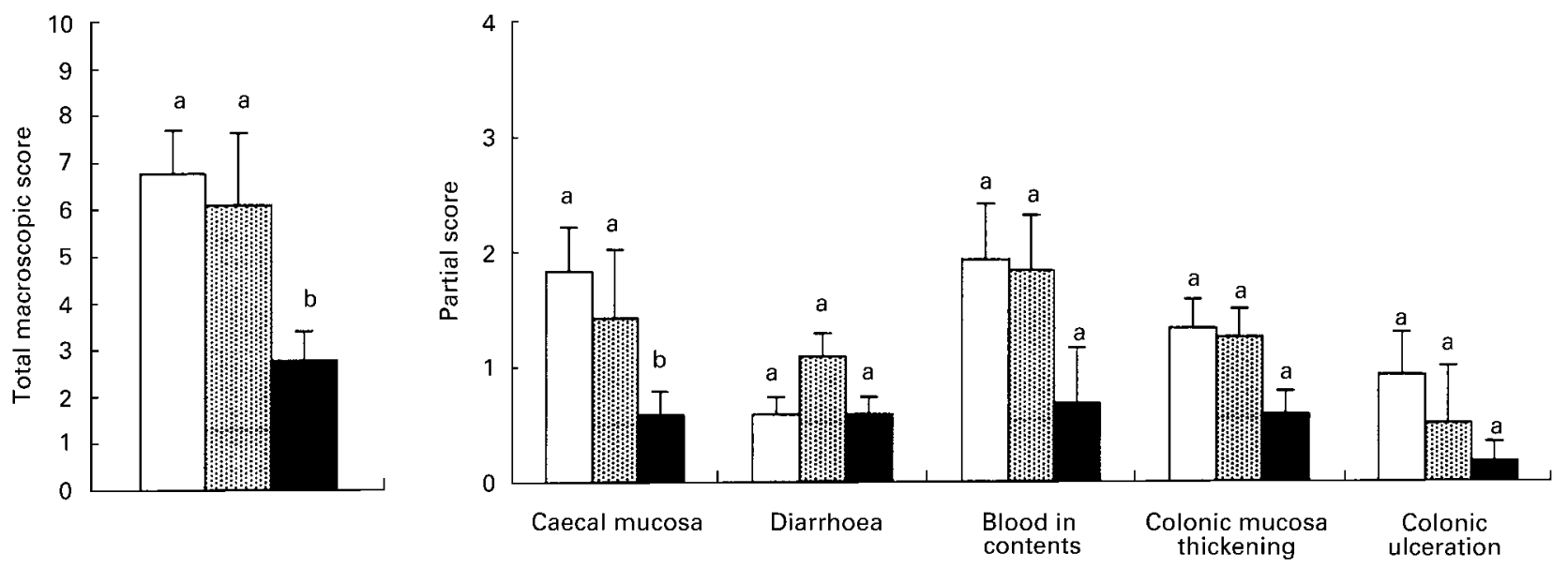

Fig. 2. Changes in the total and detailed macroscopic score of rats fed basal (BD), fructo-oligosaccharide (FOS) or resistant starch (RS) diet for $14 \mathrm{~d}$ and treated with $50 \mathrm{~g}$ dextran sulfate sodium (DSS)/I (7d) then $30 \mathrm{~g} \mathrm{DSS/l} \mathrm{for} 14 \mathrm{~d}$. $\square$, BD-DSS; 㻁, FOS-DSS; $\mathbf{\square}$, RS-DSS. For details of diets, procedures and scoring system, see Table 1, Fig. 1 and p. 77 . Values are means for six rats per group with their standard errors shown by vertical bars. ${ }^{\mathrm{a}, \mathrm{b}}$ Mean values with unlike superscript letters were significantly different: $P<0 \cdot 05$. 
(a)
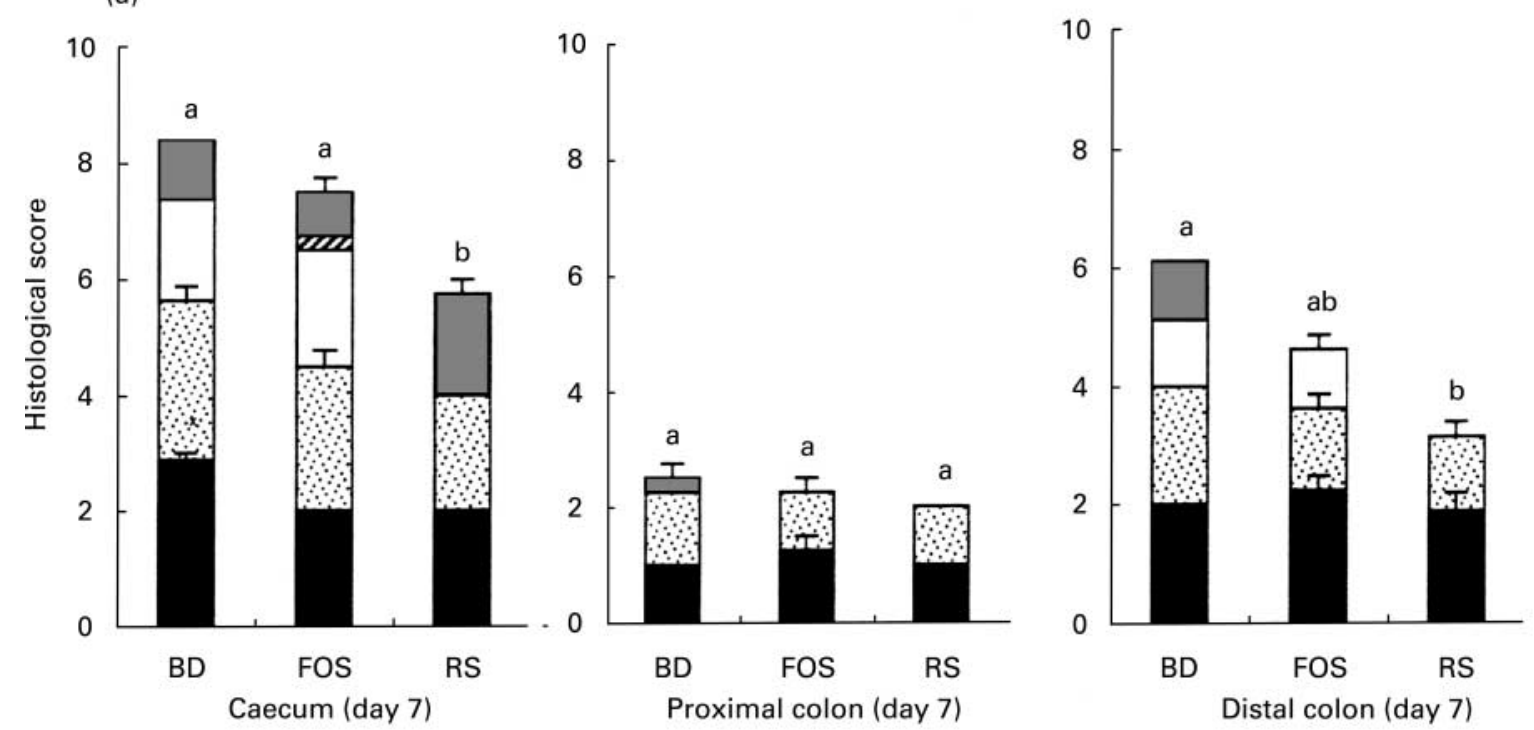

(b)
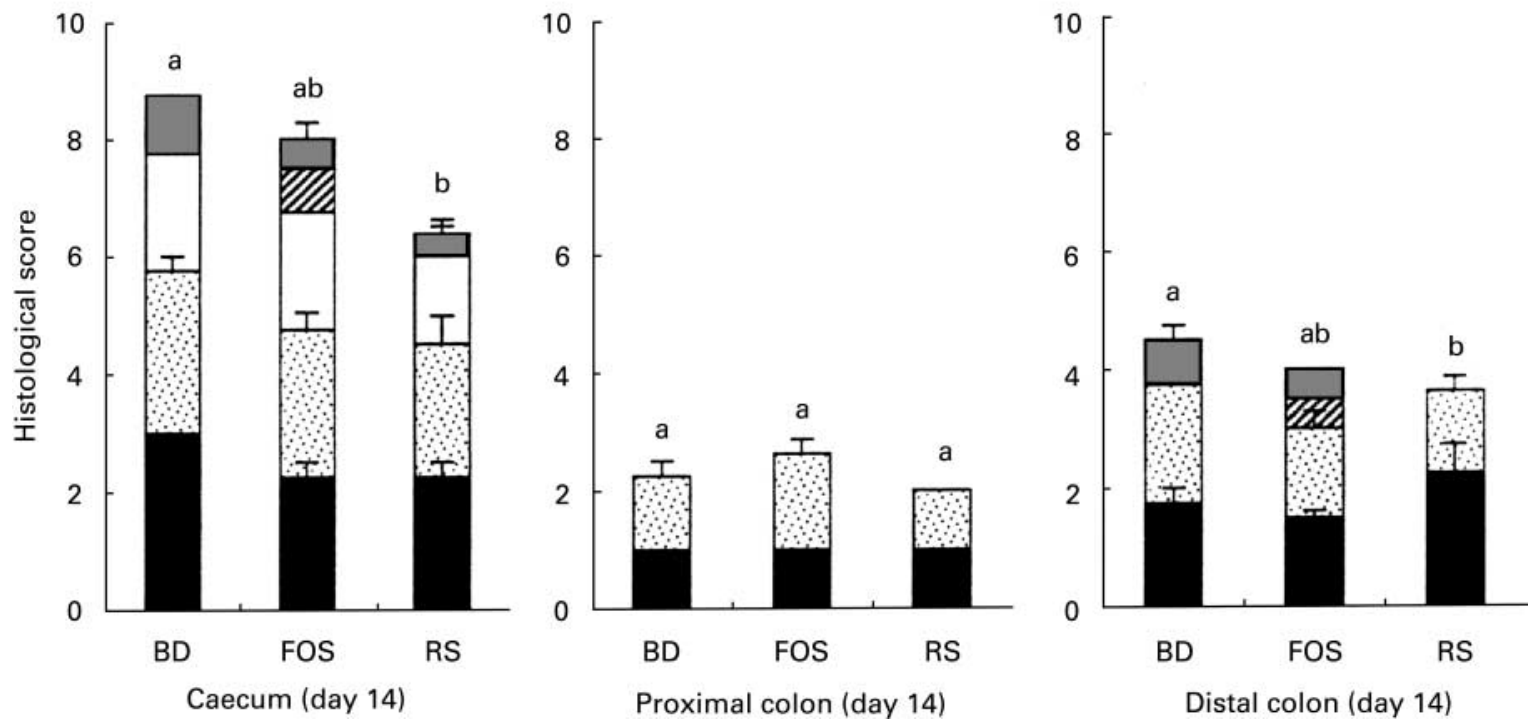

Fig. 3. Changes in the variables of the histological score of rats fed basal (BD), fructo-oligosaccharide (FOS) or resistant starch (RS) diet for 7 (day 7) (a) or 14 (day 14) (b) d and treated with $50 \mathrm{~g}$ dextran sulfate sodium (DSS)// (7 d) then $30 \mathrm{~g} \mathrm{DSS/l} \mathrm{for} 7$ (day 7 ) (a) or 14 (day 14 ) (b) d. $\square$, Goblet cell depletion; $\mathbb{Z}$, crypt abcesses; $\square$, muscle thickening; 橉, cellular infiltration; $\mathbf{\square}$, loss of mucosal architecture. For details of diets, procedures and scoring system, see Table 1, Fig. 1 and p. 77. Values are means for four rats per group. The standard errors shown by vertical bars correspond to each variable included in the histological score. ${ }^{a, b}$ Mean values of total histological score with unlike superscript letters were significantly different: $P<0.05$.

was higher compared with control rats. No molar ratio modifications were found in the RS-DSS rats compared with the RS-control rats. Concerning butyrate, it was interesting to note that its molar ratios in caecal, proximal and distal contents were not modified by the introduction of DSS when the animals were fed a fibre-enriched diet.

Effect of dextran sulfate sodium on the amount of butyrate. Because of the lack of time effect (and time $\times$ diet interaction, two-way ANOVA, $P=0.79)$ on the amount of digestive butyrate $(\mu \mathrm{mol})$, results obtained at days 7 and 14 were pooled. The amount of caecal butyrate observed in RS-DSS (38.8 (SEM 8.2) $\mu \mathrm{mol}$ ) rats was significantly higher than in BD-DSS $(9 \cdot 6$ (SEM 1.1) $\mu \mathrm{mol}$,
$P=0.0002)$ and in FOS-DSS (12.5 (SEM 2.5) $\mu \mathrm{mol}$, $P=0.0006)$. No difference among diets was observed in the proximal colon. Conversely, in the distal colon, the greatest amount of butyrate was measured in FOS-DSS rats (4.4 (SEM 0.8) $\mu \mathrm{mol})$ compared with the RS-DSS (3.9 (SEM 0.9) $\mu \mathrm{mol})$ (NS) and BD-DSS animals (2.3 (SEM 0.4) $\mu \mathrm{mol}, P=0 \cdot 0198)$.

\section{Short-chain fatty acids in portal blood}

Arterio-venous differences in SCFA are detailed in Table 5. Whatever the diet, DSS rats had a lower $\Delta$ acetate than controls, whereas $\Delta$ propionate and $\Delta$ butyrate 


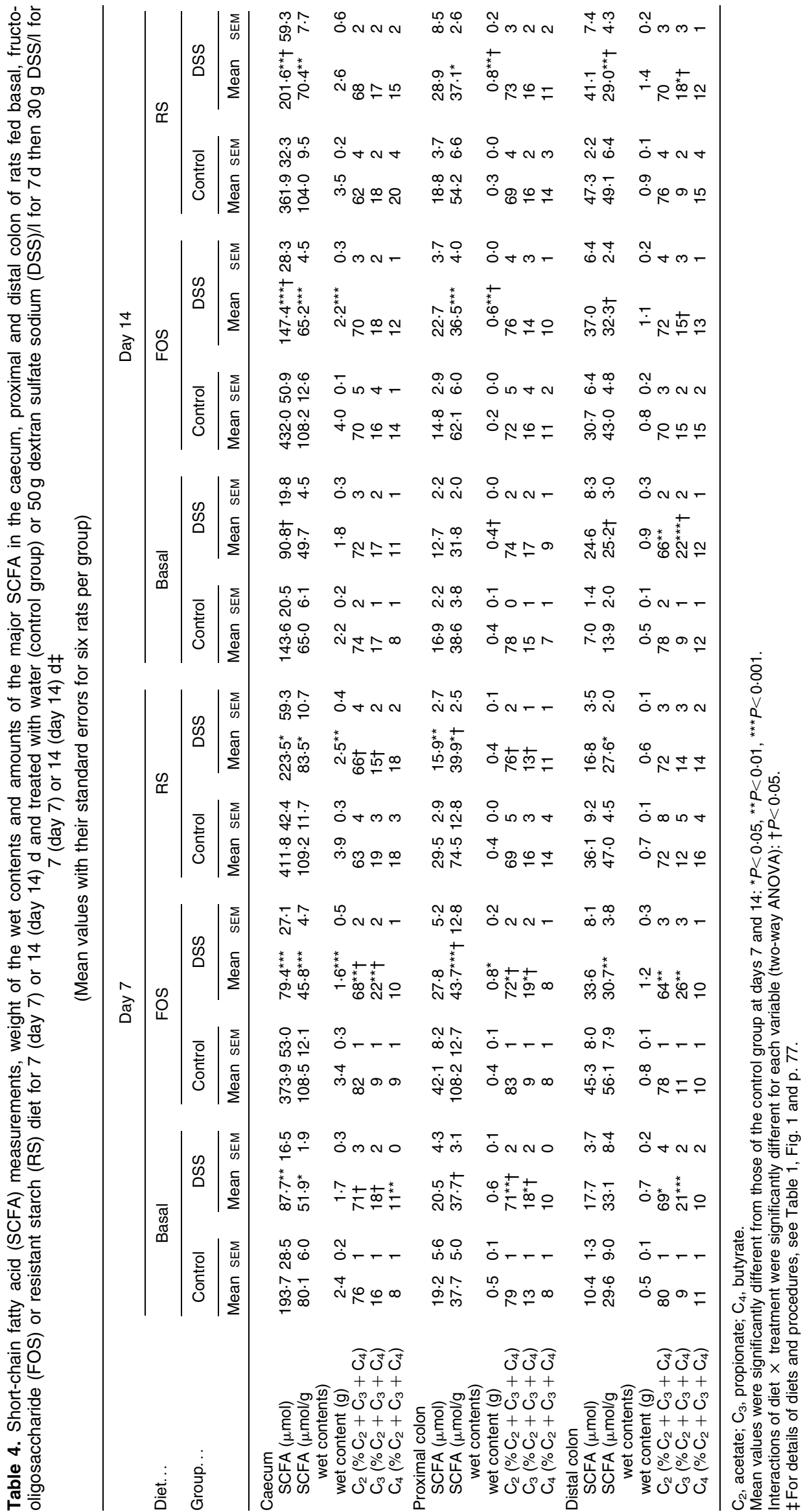


Table 5. Plasma short-chain fatty acid (SCFA) concentrations (portal - arterial) and plasma molar ratios for rats fed basal, fructooligosaccharide (FOS) or resistant starch (RS) diet for 7 or $14 \mathrm{~d}$ and treated with water (control group) or $50 \mathrm{~g}$ dextran sulfate sodium (DSS)/l for $7 \mathrm{~d}$ then $30 \mathrm{~g}$ DSS/l for 7 (day 7 ) or 14 (day 14) df

(Mean values with their standard errors for six rats per group)

\begin{tabular}{|c|c|c|c|c|c|c|c|c|c|c|c|c|}
\hline \multirow{3}{*}{$\begin{array}{l}\text { Diet... } \\
\text { Group... }\end{array}$} & \multicolumn{4}{|c|}{ Basal } & \multicolumn{4}{|c|}{ FOS } & \multicolumn{4}{|c|}{ RS } \\
\hline & \multicolumn{2}{|c|}{ Control } & \multicolumn{2}{|c|}{ DSS } & \multicolumn{2}{|c|}{ Control } & \multicolumn{2}{|c|}{ DSS } & \multicolumn{2}{|c|}{ Control } & \multicolumn{2}{|c|}{ DSS } \\
\hline & Mean & SEM & Mean & SEM & Mean & SEM & Mean & SEM & Mean & SEM & Mean & SEM \\
\hline \multicolumn{13}{|l|}{ Day 7} \\
\hline$\Delta \mathrm{C}_{2}(\mu \mathrm{M} / \mathrm{l})$ & $212 \cdot 8$ & $28 \cdot 3$ & $118 \cdot 1^{*}$ & $7 \cdot 2$ & $271 \cdot 2$ & 53.9 & $141 \cdot 6^{\star \star}$ & $10 \cdot 6$ & 277.5 & $25 \cdot 4$ & $145 \cdot 8^{\star \star}$ & $17 \cdot 2$ \\
\hline$\Delta \mathrm{C}_{3}(\mu \mathrm{M} / \mathrm{l})$ & 51.5 & 9.9 & $39 \cdot 6 \dagger$ & $5 \cdot 0$ & $52 \cdot 0$ & 9.6 & $91 \cdot 7^{*} \dagger$ & $14 \cdot 8$ & 117.6 & $18 \cdot 0$ & $39 \cdot 5^{\star \star \star} \dagger$ & 8.3 \\
\hline$\Delta \mathrm{C}_{4}(\mu \mathrm{M} / \mathrm{l})$ & $15 \cdot 6$ & 3.4 & $21 \cdot 3 \dagger$ & $2 \cdot 6$ & $30 \cdot 4$ & 9.6 & $31.5 t$ & 5.4 & $90 \cdot 0$ & $22 \cdot 2$ & $41.9^{\star \star} \dagger$ & $12 \cdot 8$ \\
\hline $\mathrm{C}_{2}\left(\% \mathrm{C}_{2}+\mathrm{C}_{3}+\mathrm{C}_{4}\right)$ & 76 & 2 & $66^{*} \dagger$ & 1 & 77 & 1 & $55^{\star \star \star} \dagger$ & 3 & 58 & 5 & $66^{*} \dagger$ & 3 \\
\hline $\mathrm{C}_{3}\left(\% \mathrm{C}_{2}+\mathrm{C}_{3}+\mathrm{C}_{4}\right)$ & 18 & 2 & $22 \dagger^{\prime}$ & 1 & 15 & 1 & $33^{\star \star \star} \dagger$ & 3 & 24 & 3 & $17^{*} \dagger$ & 1 \\
\hline $\mathrm{C}_{4}\left(\% \mathrm{C}_{2}+\mathrm{C}_{3}+\mathrm{C}_{4}\right)$ & 5 & 1 & $12^{*}$ & 1 & 8 & 1 & 12 & 2 & 18 & 4 & 17 & 2 \\
\hline \multicolumn{13}{|l|}{ Day 14} \\
\hline$\Delta \mathrm{C}_{2}(\mu \mathrm{M} / \mathrm{l})$ & $164 \cdot 0$ & 9.5 & $126 \cdot 4$ & 6.5 & 262.9 & $36 \cdot 4$ & $154 \cdot 8^{\star \star}$ & $16 \cdot 0$ & 274.9 & $36 \cdot 6$ & $166 \cdot 5^{\star \star}$ & $30 \cdot 2$ \\
\hline$\Delta \mathrm{C}_{3}(\mu \mathrm{M} / \mathrm{l})$ & 37.4 & $5 \cdot 0$ & 58.9 & $12 \cdot 0$ & $82 \cdot 2$ & 23.5 & 53.9 & $9 \cdot 1$ & $119 \cdot 6$ & $36 \cdot 6$ & $64 \cdot 7$ & $14 \cdot 0$ \\
\hline$\Delta \mathrm{C}_{4}(\mu \mathrm{M} / \mathrm{l})$ & $7 \cdot 7$ & $2 \cdot 5$ & $32 \cdot 5$ & 5.9 & $63 \cdot 3$ & $26 \cdot 5$ & 34.5 & $5 \cdot 3$ & 66.5 & $14 \cdot 1$ & $51 \cdot 8$ & $18 \cdot 3$ \\
\hline $\mathrm{C}_{2}\left(\% \mathrm{C}_{2}+\mathrm{C}_{3}+\mathrm{C}_{4}\right)$ & 79 & 2 & $60^{\star *} \dagger$ & 4 & 67 & 4 & $64 \dagger$ & 3 & 60 & 4 & $61 \dagger$ & 5 \\
\hline $\mathrm{C}_{3}\left(\% \mathrm{C}_{2}+\mathrm{C}_{3}+\mathrm{C}_{4}\right)$ & 17 & 1 & $26^{*}$ & 3 & 20 & 2 & 22 & 2 & 23 & 4 & 23 & 2 \\
\hline $\mathrm{C}_{4}\left(\% \mathrm{C}_{2}+\mathrm{C}_{3}+\mathrm{C}_{4}\right)$ & 3 & 1 & $14^{\star \star}$ & 0 & 13 & 3 & 14 & 1 & 16 & 4 & 16 & 4 \\
\hline
\end{tabular}

$\Delta \mathrm{C}_{2}$, arterio-venous difference for acetate; $\Delta \mathrm{C}_{3}$, arterio-venous difference for propionate; $\Delta \mathrm{C}_{4}$, arterio-venous difference for butyrate. Mean values were significantly different from those of the control group for each diet: ${ }^{\star} P<0.05,{ }^{\star \star} P<0.01,{ }^{\star \star \star} P<0.001$

Interactions of diet $x$ treatment were significantly different for each variable (two-way ANOVA): $† P<0.05$

$\ddagger$ For details of diets and procedures, see Table 1, Fig. 1 and p. 77.

appeared to be less affected by the DSS treatment. Major changes concerned RS-DSS rats at day 7: this group had a significantly $(P<0.05)$ lower $\Delta$ acetate, $\Delta$ propionate and $\Delta$ butyrate than their corresponding control group. Interestingly, butyrate molar ratios did not vary with DSS when rats were fed the FOS- and RS-enriched diet.

\section{Discussion}

The effect of butyrate on the health of the mucosa is well known and its role appears to be multi-factorial. Indeed, its role in the colonic immune system has been shown recently and appears to be increasingly well documented (for example via interactions with cytokines (Nancey et al. 2002), lymphocytes (Chapman, 2001), neutrophils (Liu et al. 2001) or nuclear factor-кB (Segain et al. 2000) etc.). The trophic effect of butyrate on the inflamed colonic mucosa has been described in several studies. Most of them used butyrate enemas in patients with ulcerative colitis (Breuer et al. 1991; Scheppach et al. 1992; Steinhart et al. 1994) or in animals (Butzner et al. 1996). But, interestingly, there was no effect when butyrate was given to inflamed rats by per os administration (Kanauchi et al. 1999). As colonic butyrate administration is too invasive for human therapy, an interesting alternative for colonic treatment could be dietary fibre. Some fibres, such as those in Plantago ovata seeds in patients with ulcerative colitis (Fernandez-Banares et al. 1999) and pectin (Andoh et al. 1999) and germinated-barley foodstuff in DSS-induced colitis (Kanauchi et al. 1999; Araki et al. 2000a,b; Kanauchi et al. 2001), showed promising results that are, according to the authors, partly explained by the trophic action of butyrate.
Conversely, fermentation of short-chain FOS (Le Blay et al. 1999b) and RS (Le Blay et al. 1999a) are known to yield high levels of butyrate. Results obtained in models of inflammatory bowel disease (trinitrobenzene sulfonic acid-induced) indicated that FOS (Cherbut et al. 2003) and RS (granulated pea-starch) (Jacobasch et al. 1999) are good candidates for the treatment of the inflamed epithelial mucosa. FOS (Gallaher et al. 1996; Pierre et al. 1997; Perrin et al. 2001) and RS (Perrin et al. 2001) have also shown beneficial properties against colon carcinogenesis, even if the impact of RS seems controversial (Sakamoto et al. 1996; Pierre et al. 1997).

Our results presented here focus on the effect of FOS and RS on the digestive mucosa inflamed by DSS. Histopathological characteristics of injuries observed in this model concern the distal colon and predominantly the caecum (Moreau et al. 2002). Macroscopic and histological results showed no caeco-colonic mucosal repair with FOS neither at day 7 nor at 14 compared with the BD. Conversely, macroscopic and histological results indicated that RS diet can provide beneficial effects on the chronic inflamed caecal and distal mucosa. This seemed to appear as soon as $7 \mathrm{~d}$ (day 7) and persisted throughout the experiment. This RS healing effect against DSS damage was significant compared with the fibre-free $\mathrm{BD}$, but also compared with the FOS-supplemented diet. As proximal injuries induced in this DSS model were few (Moreau et al. 2002), it is not surprising that dietary manipulations had a minor effect on the proximal colon.

The differing histopathological consequences of a FOS or RS supplementation could be suspected to be linked with some possible bias, such as food consumption differences. It appeared that this effect cannot be explained by 
differences either in diet or in DSS consumption. We observed identical food consumption for the three DSStreated groups between days 0 and 7, whereas food consumption of FOS-DSS rats was lower than the RS-DSS group between days 7 and 14 (Table 2). Simultaneously, histological analysis indicated that the first signs of mucosal healing appeared at day 7 for the RS-DSS groups, whereas the inflammation observed in FOS-DSS rats was always more severe. This suggests that the lower food consumption observed in FOS-DSS rats could be a consequence of the changes in the inflammation process compared with RS-DSS rats. It is probably not a causal event explaining the lack of healing effect of FOS diet on the injured mucosa. Moreover, the water:diet intake ratio remained constant among groups.

Many hypotheses could be proposed to explain, at least in part, the difference of effect between FOS and RS on the inflamed mucosa. Among them, differences in caecocolonic SCFA profiles and concentrations yielded after fermentation of the tested diets could be proposed. Considering only DSS-treated rats, our present results underlined discrepancies in SCFA measurements between diets. The amount of caecal SCFA ( $\mu \mathrm{mol})$ measured at day 7 in FOS-DSS rats was considerably lower than in RS-DSS rats (results were equivalent at day 14). Moreover, at day 7 as well as 14, there was proportionally less butyrate in the caecum of FOS-DSS rats than in RS-DSS rats, which could partially explain the lack of benefit of FOS observed in the caecal mucosa. Nevertheless, it is interesting to note that in FOS-DSS rats, despite a higher level of butyrate in the distal colon compared with the other diets, no improvement of distal histological scores was observed. Consequently, the caecal fermentation appears to be essential for the healing process.

After 7 and $14 \mathrm{~d}$ of chronic colitis, our present results indicated that the DSS treatment inhibits the fermentation process, SCFA measurements (amount or concentrations) being lower in DSS rats than in controls (except for BD rats at day 14). Consequently, to be efficient, dietary fibre-containing diets must yield sufficient butyrate to counteract the inhibition of fermentation caused by DSS inflammation. These results underline the fact that the efficiency of dietary fibre against DSS injuries seems to be partly related to their fermentation characteristics.

Another possible explanation of the difference between FOS and RS could concern the luminal composition and particularly sulfate-reducing bacteria. They have been reported to colonise the large intestine in ulcerative colitis (Pitcher et al. 1995; Roediger et al. 1997) and to generate high levels of sulfides, sulfites and mercaptans (Roediger \& Nance, 1990; Roediger et al. 1997). Some of these compounds may inhibit the butyrate uptake by the colonocytes (Stein et al. 1995; Jacobasch et al. 1999) and the colonic butyrate oxidation (Roediger et al. 1993a,b, 1996; Pitcher \& Cummings, 1996) leading to an alteration of the mucosal integrity (Roediger, 1995).

Sulfate-reducing bacteria prefer near neutral $\mathrm{pH}$ conditions and sulfate reduction is optimal at alkaline $\mathrm{pH}$ (Widdel, 1988). By decreasing caeco-colonic $\mathrm{pH}$ with the production of SCFA, FOS and RS could inhibit the action of sulfate-reducing bacteria. Moreover, RS (Brown et al. 1997; Kleessen et al. 1997; Cresci et al. 1999) and FOS (Djouzi \& Andrieux, 1997; Le Blay et al. 1999b; Marx et al. 2000) are available to stimulate the growth of lactic-acid bacteria such as Bifidobacteria and Lactobacilli. On one hand, they contribute to a decrease in digestive $\mathrm{pH}$, and on the other hand, Lactobacteria have been reported to inhibit sulfate-reducing bacteria. These reasons may indicate that both RS and FOS may be of great interest for the inflamed mucosa. However, our present results showed that only the RS-supplemented diet was effective, suggesting that this effect cannot be exclusively attributable to its interaction with the luminal microflora. To explain the RS effect, it could be hypothesised that the digestive $\mathrm{pH}$ obtained after $\mathrm{RS}$ ingestion could rapidly reach a steady state, while $\mathrm{pH}$ obtained after FOS ingestion would be more unsteady. Moreover, it was previously shown that colonic mucin synthesis increased with butyrate (Finnie et al. 1995) and lower $\mathrm{pH}$ may also stimulate mucus production (Bustos-Fernandez et al. 1978). As the amount of butyrate in the caecum with the RS diet is higher than with FOS, the higher production of mucus should be one of the hypothetical factors of mucosa protection.

In conclusion, a dietary RS supply induced significant improvement in macroscopic and histological characteristics of caeco-colonic inflammatory lesions due to DSS in rats. This could therefore confirm the interest in substrates generating high levels of butyrate during their colonic fermentation in inflammatory bowel disease. According to our present results, the effect of RS could be partially explained by higher amounts of caecal SCFA and especially butyrate. The ineffectiveness of the FOS-supplemented diet underlines the importance of the type of dietary substrate. Obviously, all the substrates susceptible to be fermented producing a high proportion of butyrate are not equivalent as far as their healing properties on DSS inflammation are concerned.

\section{Acknowledgements}

The authors acknowledge National Starch and Chemical Ltd for providing the Novelose 330 and the competent technical assistance of Thérèse Frégier, Sigrid Parois and Philippe Bleis during the study.

\section{References}

Ahmad MS, Krishnan S, Ramakrishna BS, Mathan M, Pulimood AB \& Murthy SN (2000) Butyrate and glucose metabolism by colonocytes in experimental colitis in mice. Gut 46, 493-499.

Andoh A, Bamba T \& Sasaki M (1999) Physiological and antiinflammatory roles of dietary fiber and butyrate in intestinal functions. J Parenter Enteral Nutr 23, S70-S73.

Appleyard CB \& Wallace JL (1995) Reactivation of hapteninduced colitis and its prevention by anti-inflammatory drugs. Am J Physiol 269, G119-G125.

Araki Y, Andoh A, Koyama S, Fujiyama Y, Kanauchi O \& Bamba T (2000a) Effects of germinated barley foodstuff on microflora and short-chain fatty acid production in dextran 
sulfate sodium-induced colitis in rats. Biosci Biotechnol Biochem 64, 1794-1800.

Araki Y, Fujiyama Y, Andoh A, Koyama S, Kanauchi O \& Bamba $\mathrm{T}$ (2000b) The dietary combination of germinated barley foodstuff plus Clostridium butyricum suppresses the dextran sulfate sodium-induced experimental colitis in rats. Scand J Gastroenterol 35, 1060-1067.

Basson MD \& Sgambati SA (1998) Effects of short-chain fatty acids on human rectosigmoid mucosal colonocyte brushborder enzymes. Metabolism 47, 133-134.

Breuer RI, Buto SK, Christ ML, et al. (1991) Rectal irrigation with short-chain fatty acids for distal ulcerative colitis. Preliminary report. Dig Dis Sci 36, 185-187.

Brighenti F (1997) Simple method for quantitative analysis in short chain fatty acids in serum by gas liquid chromatography. In Plant Polysaccharides in Human Nutrition: Structure, Function, Digestive Fate and Metabolic Effects, pp. 114-119 [F Guillon, G Abraham, R Amado et al., editors]. Nantes: J. Agro-Industrial Research.

Brown I, Warhurst M, Arcot J, Playne M, Illman RJ \& Topping DL (1997) Fecal numbers of bifidobacteria are higher in pigs fed Bifidobacterium longum with a high amylose cornstarch than with a low amylose cornstarch. J Nutr 127, $1822-1827$.

Bustos-Fernandez L, de Paolo IL \& Hamamura S, et al. (1978) Does secretin influence rat colonic absorption and secretion? Am J Gastroenterol 70, 265-269.

Butzner JD, Parmar R, Bell CJ \& Dalal V (1996) Butyrate enema therapy stimulates mucosal repair in experimental colitis in the rat. Gut 38, 568-573.

Chapman MA (2001) The role of the colonic flora in maintaining a healthy large bowel mucosa. Ann $R$ Coll Surg Engl 83, $75-80$.

Chapman MA, Grahn MF, Boyle MA, Hutton M, Rogers J \& Williams NS (1994) Butyrate oxidation is impaired in the colonic mucosa of sufferers of quiescent ulcerative colitis. Gut 35, 73-76.

Cherbut C, Michel C \& Lecannu G (2003) The prebiotic characteristics of fructooligosaccharides are necessary for reduction of TNBS-induced colitis in rats. $J$ Nutr 133, 21-27.

Clausen MR \& Mortensen PB (1994) Kinetic studies on the metabolism of short-chain fatty acids and glucose by isolated rat colonocytes. Gastroenterology 106, 423-432.

Cresci A, Orpianesi C, Silvi S, Mastrandrea V \& Dolara P (1999) The effect of sucrose or starch-based diet on short-chain fatty acids and faecal microflora in rats. J Appl Microbiol 86, 245-250.

Demigné C \& Rémésy C (1982) Influence of unrefined potato starch on cecal fermentations and volatile fatty acid absorption in rats. $J$ Nutr 112, 2227-2234.

Den Hond E, Hiele M, Evenepoel P, Peeters M, Ghoos Y \& Rutgeerts P (1998) In vivo butyrate metabolism and colonic permeability in extensive ulcerative colitis. Gastroenterology 115, 584-590.

Djouzi Z \& Andrieux C (1997) Compared effects of three oligosaccharides on metabolism of intestinal microflora in rats inoculated with a human faecal flora. Br J Nutr 78, 313-324.

Fernandez-Banares F, Hinojosa J \& Sanchez-Lombrana JL, et al. (1999) Randomized clinical trial of Plantago ovata seeds (dietary fiber) as compared with mesalamine in maintaining remission in ulcerative colitis. Spanish Group for the Study of Crohn's Disease and Ulcerative Colitis (GETECCU). Am J Gastroenterol 94, 427-433.

Finnie I, Dwarakanath A, Taylor B \& Rhodes J (1995) Colonic mucin synthesis is increased by sodium butyrate. Gut 36, 93-99.
Firmansyah A, Penn D \& Lebenthal E (1989) Isolated colonocyte metabolism of glucose, glutamine, $n$-butyrate, and betahydroxybutyrate in malnutrition. Gastroenterology 97, $622-629$.

Fleming SE, Fitch MD, DeVries S, Liu ML \& Kight C (1991) Nutrient utilization by cells isolated from rat jejunum, cecum and colon. $J$ Nutr 121, 869-878.

Frankel W, Lew J \& Su B, et al. (1994) Butyrate increases colonocyte protein synthesis in ulcerative colitis. J Surg Res 57, 210-214.

Gallaher DD, Stallings WH, Blessing LL, Busta FF \& Brady LJ (1996) Probiotics, cecal microflora, and aberrant crypts in the rat colon. J Nutr 126, 1362-1371.

Jacobasch G, Schmiedl D, Kruschewski M \& Schmehl K (1999) Dietary resistant starch and chronic inflammatory bowel diseases. Int J Colorectal Dis 14, 201-211.

Kanauchi O, Iwanaga T, Andoh A, et al. (2001) Dietary fiber fraction of germinated barley foodstuff attenuated mucosal damage and diarrhea, and accelerated the repair of the colonic mucosa in an experimental colitis. J Gastroenterol Hepatol 16, 160-168.

Kanauchi O, Iwanaga T, Mitsuyama K, et al. (1999) Butyrate from bacterial fermentation of germinated barley foodstuff preserves intestinal barrier function in experimental colitis in the rat model. J Gastroenterol Hepatol 14, 880-888.

Kleessen B, Stoof G, Proll J, Schmiedl D, Noack J \& Blaut M (1997) Feeding resistant starch affects fecal and cecal microflora and short-chain fatty acids in rats. J Anim Sci $\mathbf{7 5}$, 2453-2462.

Le Blay G, Michel C, Blottiere HM \& Cherbut C (1999a) Enhancement of butyrate production in the rat caecocolonic tract by long-term ingestion of resistant potato starch. $\mathrm{Br} J$ Nutr 82, 419-426.

Le Blay G, Michel C, Blottiere HM \& Cherbut C (1999b) Prolonged intake of fructo-oligosaccharides induces a short-term elevation of lactic acid-producing bacteria and a persistent increase in cecal butyrate in rats. $J$ Nutr 129, 2231-2235.

Liu Q, Shimoyama T, Suzuki K, Umeda T, Nakaji S \& Sugawara K (2001) Effect of sodium butyrate on reactive oxygen species generation by human neutrophils. Scand $J$ Gastroenterol 36, 744-750.

Marx SP, Winkler S \& Hartmeier W (2000) Metabolization of beta-(2,6)-linked fructose-oligosaccharides by different bifidobacteria. FEMS Microbiol Lett 182, 163-169.

Moreau N, Toquet C, Laboisse C, et al. (2002) Predominance of caecal injury in a new dextran sulfate sodium treatment in rats: histopathological and fermentative characteristics. Eur $J$ Gastroenterol Hepatol 14, 535-542.

Nancey S, Bienvenu J, Coffin B, Andre F, Descos L \& Flourie B (2002) Butyrate strongly inhibits in vitro stimulated release of cytokines in blood. Dig Dis Sci 47, 921-928.

Pierre F, Perrin P, Champ M, Bornet F, Meflah K \& Menanteau J (1997) Short-chain fructo-oligosaccharides reduce the occurrence of colon tumors and develop gut-associated lymphoid tissue in Min mice. Cancer Res 57, 225-228.

Perrin P, Pierre F, Patry Y, et al. (2001) Only fibres promoting a stable butyrate producing colonic ecosystem decrease the rate of aberrant crypt foci in rats. Gut 48, 53-61.

Pitcher MC \& Cummings JH (1996) Hydrogen sulphide: a bacterial toxin in ulcerative colitis? Gut 39, 1-4.

Pitcher MCL, Beatty ER \& Gibson GR (1995) Incidence and activities of sulphate-reducing bacteria in patients with ulcerative colitis. Gut 36, A63.

Roediger WE (1980a) Role of anaerobic bacteria in the metabolic welfare of the colonic mucosa in man. Gut 21, 793-798. 
Roediger WE (1980b) The colonic epithelium in ulcerative colitis: an energy-deficiency disease? Lancet 2, 712-715.

Roediger WE (1982) Utilization of nutrients by isolated epithelial cells of the rat colon. Gastroenterology 83, 424-429.

Roediger WE (1993) The imprint of disease on short-chain fatty acid metabolism by colonocytes. In Short-chain Fatty Acids, Proceedings of the 73rd Falk Symposium, 1989, pp. 195-205 [HJ Binder, J Cummings and K Soergel, editors]. DorDrecht, The Netherlands: Kluwer Academic Publishers.

Roediger WE (1995) The place of short-chain fatty acids in colonocyte metabolism in health and ulcerative colitis: the impaired conocyte barrier. In Physiological and Clinical Aspects of Short-chain fatty acids, pp. 337-351 [J Cummings, J Rombeau and T Sakata, editors]. Cambridge, MA: Cambridge University Press.

Roediger WE, Babidge W \& Millard S (1996) Methionine derivatives diminish sulphide damage to colonocytes - implications for ulcerative colitis. Gut 39, 77-81.

Roediger WE, Duncan A, Kapaniris O \& Millard S (1993a) Reducing sulfur compounds of the colon impair colonocyte nutrition: implications for ulcerative colitis. Gastroenterology 104, 802-809.

Roediger WE, Duncan A, Kapaniris O \& Millard S (1993b) Sulphide impairment of substrate oxidation in rat colonocytes: a biochemical basis for ulcerative colitis? Clin Sci (Lond) 85, $623-627$.

Roediger WE, Moore J \& Babidge W (1997) Colonic sulfide in pathogenesis and treatment of ulcerative colitis. Dig Dis Sci 42, $1571-1579$.

Roediger WE \& Nance S (1990) Selective reduction of fatty acid oxidation in colonocytes: correlation with ulcerative colitis. Lipids 25, 646-652.
Sakamoto J, Nakaji S, Sugawara K, Iwane S \& Munakata A (1996) Comparison of resistant starch with cellulose diet on 1,2-dimethylhydrazine-induced colonic carcinogenesis in rats. Gastroenterology 110, 116-120.

Sakata T (1987) Stimulatory effect of short-chain fatty acids on epithelial cell proliferation in the rat intestine: a possible explanation for trophic effects of fermentable fibre, gut microbes and luminal trophic factors. Br J Nutr 58, 95-103.

Scheppach W, Muller JG, Boxberger F, et al. (1997) Histological changes in the colonic mucosa following irrigation with short-chain fatty acids. Eur J Gastroenterol Hepatol 9, $163-168$.

Scheppach W, Sommer H, Kirchner T, et al. (1992) Effect of butyrate enemas on the colonic mucosa in distal ulcerative colitis. Gastroenterology 103, 51-56.

Segain JP, Raingeard de la Bletiere D, Bourreille A, et al. (2000) Butyrate inhibits inflammatory responses through NFKB inhibition: implications for Crohn's disease. Gut 47, 397-403.

Stein J, Schroder O, Milovic V \& Caspary WF (1995) Mercaptopropionate inhibits butyrate uptake in isolated apical membrane vesicles of the rat distal colon. Gastroenterology 108, 673-679.

Steinhart AH, Brzezinski A \& Baker JP (1994) Treatment of refractory ulcerative proctosigmoiditis with butyrate enemas. Am J Gastroenterol 89, 179-183.

Tappenden KA \& McBurney MI (1998) Systemic short-chain fatty acids rapidly alter gastrointestinal structure function, and expression of early response genes. Dig Dis Sci 43, 1526-1536.

Widdel F (1988) Microbiology and ecology of sulfate- and sulfurreducing bacteria. In Biology of Anaerobic Microorganisms, pp. 469-585 [AJB Zehnder, editor]. New York: John Wiley and Sons. 